\title{
Pathways to mental health care in KwaZulu - Natal
}

\author{
LP Mkize, M Cur, School of Nursing, University of Natal \\ LR Uys, D Soc Sc, School of Nursing, University of Natal
}

\section{Abstract}

The understanding of popular beliefs about mental health care and the pathways clients take prior to admission to a mental health institution is vital in planning to reduce delays in seeking treatment. The objectives of this exploratory survey were to determine pathways of care the clients with mental illness take, which ultimately lead to the mental health institution, the effects of socio-cultural and economic factor on the pathways to mental health care and the satisfaction with different service providers consulted.

Data was gathered through semi-structured interviews.

The results indicate that African clients interpret mental illness as bewitchment. Delays in seeking appropriate mental health care are experienced because traditional and faith healers are the first port of call. The short pathways are used when the first signs of psychotic features are severe, including like aggressive or violent behaviour. Financial constraints seem to be the problem for most of the clients in accessing mental health care. Furthermore, defaulting treatment was also observed due to the fact that mental illnesses are stigmatised in African communities.

\section{Introduction}

The understanding of the pathways that clients take prior to admission to a mental health institution is a vital factor in planning to reduce delays in seeking treatment. Studying the pathways helps in the identifying of sources of delays in the receiving of care, and suggest possible improvements. Pathways to mental health care reflect the nature of health services, affordability, accessibility and availability of mental health professionals (psychiatrists, psychiatric nurses, psychologists, social workers and occupational therapists). The study of pathways to mental health care is important in elucidating popular beliefs about mental illness (Gureje, Acha, and Odejide, 1995:125).

The identification of cultural differences at basic levels is of importance in connection with the creation and transformation of mental health services in the new South Africa (Swartz, 1998:13; Patel, 1995:35). The pathways which patients take, are likely to be influenced by conventions governing referral by relationships which exist between mental health services, other sources of help and also by the availability of mental health and other supporting facilities. Access to mental health care continues to be a problem to the aged, the poor and rural Black population. This is largely due to financial affordability, location of services and transport costs to reach the required service (Gater, De Almeida,Sousa, Barrientos, Caraveo, Chandrashekar, Dhadphale, Goldberg, Al Kathiri, Mubbashar, Silhan, Thong, Torres-Gonzales and Sartorius, 1991:761).
It has been observed that episodes of mental disorders are fairly common in the population, but mental health professionals see only a minority of these people. Furthermore, a sizable proportion of those with psychological problems are not identified but remain undetected in the community (Casey, 1990:1). The majority of people consulted their doctors, although they often do so for associated physical symptoms that are causing them distress. A model that consists of five levels and four filters between levels, each corresponding to a stage on the pathway to mental health care was developed by Goldberg and Huxley ( 1992:4).

In the African society, when people fall sick, they report this to those around them. They observe the symptoms based on whether they are minor ailments that could be treated at home, or a serious illness that needs the attention of an expert. The severity of illness is assessed by the behaviour of the person. If a sick person continues to work. she/he is sick but goes with it (uhamba nakho). If she/he is confined to bed, (ulele phansi) the illness is considered serious to those around him/her (Ngubane, 1977:100). The financial status of the client also plays a major role in determining the seeking of relevant help and the availability of the desired mental health service.

The decision to contact a western doctor or a traditional/ spiritual healer is influenced by factors such as the seriousness of the illness, availability of health services, financial implications and the person responsible for the decision. It is important to note that there will be delays in consultation since the head of the family especially in the African community is usually away from home; for exam- 
ple. he would be a migrant labourer in another city.

\section{Research goal}

The goal of the study is to increase the understanding of health professionals of pathways to care taken by clients before they are admitted to a mental health institution and to enhance health service planning

\section{Objectives}

- To determine pathways of care that clients with mental illness take which ultimately led to the mental health institution.

- To determine the effects of socio-cultural and economic factors on pathways to mental health care.

- To determine satisfaction with different service providers consulted.

\section{Terminology}

\section{Pathway}

Chambers student dictionary (1989:1525) define pathway as either a route taken by people on foot. a track or a course of action or conduct. In this study, pathway is defined as the implementation of actions and individual's conduct towards the early detection of mental illness.

\section{African people}

According to this study African people refers to the Blacks who are sharing the same cultural background, norms, values and beliefs as Africans.

\section{African ways}

Swartz (1998:212-213) defines the African ways as the traditional views that underpin the causes of mental illness. These views of mental illness are described as the disturbance in the whole being, also taking into account the powers of protection of the ancestors, witchcraft and spirit forces.

\section{The conceptual framework}

The study is guided by the five levels and four filters model which was designed by Goldberg and Huxley (1992:4). These researchers postulate that the majority of mental illnesses seen on community surveys has not been seen by mental health care services. They had concluded that there is a filtering process in operation between the community and the wards of the psychiatric hospital, which is selectively permeable to those with more severe disorders. According to these researchers most clients are referred to the mental health care services by other professionals. This means that there is also another filter between the community and the referring professionals, as well as between the professional and the mental health services.

\section{Level one: The community general illness}

\section{$1^{\text {st }}$ Filter: The identification of illness}

All mental illnesses such as: depressive illness, anxietyrelated disorders, organic mental disorders, schizophrenia and bipolar affective disorders are encountered in a community. These mental illnesses cause enormous suffering. are chronic and cause severe disability.

The first filter, which deals with identification of illness, is present in the community. Some clients remain at this level and do not pass the filter because they do not identify their suffering as illness and do not consult the formal health system. They consult traditional/faith healers. Casey (1990: 10) emphasizes the fact that symptom severity is one factor that prompted consultation and who one should consult, although many other factors are involved.

\section{Level Two: Total mental morbidity- attenders in PHC}

\section{$2^{\text {nd }}$ Filter: Ability to identify disorder}

At this level clients go to Primary Health Clinics where mental health professionals are able to detect psychological distress or mental illness. Many clients reach this level but are not filtered through because of their physical symptomatology presentation, and lack of skill in PHC care providers in identifying psychological distress.

\section{Level Three: Mental disorders identified by doctors (conspicuous psychiatric morbidity) \\ $3^{\text {rd }}$ Filter: Referral to mental illness service}

At this level the clients are mentally ill and are therefore seeking help, treatment and admission. The level of care here is at a more specialized level, but could still be in the community. The filter here is whether the client, who had been identified as having a mental health problem (filter 2) was referred for specialized help (filter 3 ).

\section{Level Four: Total morbidity- mental illness service. \\ $4^{\text {th }}$ Filter: Admission to psychiatric hospitals}

At this level the client passes through level three and is admitted in a mental health institution.

\section{Level Five: Psychiatric-in-patients}

These are the clients that had filtered and passed through all levels and are admitted in a mental health institution for a period of time. The level is therefore specialized in patient care.

\section{Research design}

An exploratory survey research design was used to explore and analyse the pathways to mental health care taken by clients, seeking help before being admitted to a mental health institution. Polit and Hungler, (1999:716) and Wilson (1985:145) define survey research design as a non-experimental research that focuses on obtaining information re- 
garding the activities, beliefs, preferences and attitudes of people through direct questioning of sample of respondents. Survey focuses on what people do, how they care for their health needs, their compliance in taking medication and what kinds of family planning behaviours they engage in. Any information that could reliably be obtained by directly asking a person for that information is acceptable for inclusion in a survey. The data was gathered through semistructured interviews.

\section{Setting}

The target population for the study was first time admissions to a mental health institution in Pietermaritzburg, excluding those clients with dementia. The targeted population was the male and female clients from the pre-discharge units of the hospital. The pre-discharge units were targeted because the clients are no longer psychotic and aggressive, and could therefore relate well to the researcher. This was the group's first admission to a mental hospital and it was hoped that they would be able to trace their pathways from the time of the onset of mental illness to the time of their admission to a mental health institution.

\section{Sample}

A purposive sample of fifteen clients was selected to participate in the study. Burns \& Grove (1987:218) state that a purposive sample is the selection of participants as judged by the researcher as having the necessary knowledge and experience to contribute meaningful data to the study. It was assumed that this particular sample would provide adequate information in identifying major trends in help seeking behaviour when first signs and symptoms of mental illness occurred.

It was also hoped that their memories were intact so they could be able to relate their choices and decisions made during the course of their mental illness. It was also important to note that the researcher could have experienced difficulties during the interviews, and therefore a large sample could not be planned.

The client selection depended on those that were in both female and male pre-discharge units on the third and fourth weekends of October $200 \mathrm{l}$ and the first weekend of November 2001 . These were the weekends that were utilized to collect data for the study.

\section{Instrument}

The instrument for this research was a questionnaire beginning with demographic data about the client. Throw away questions were used to develop trust and rapport with the client; for example asking about the weather. A semi-structured interview guide was developed to explore the pathways clients took to mental health care services. It was written in English and translated into Zulu. The instrument consisted of four questions that were related to the levels and filters of the conceptual framework adopted from Goldberg and Huxley (1992:4); for instance,

Probing questions were used to gather more information and explanations. Open- ended questions were asked to ensure that the clients were encouraged to give more information for example: "Tell me about getting help...".

\section{Validity and reliability}

A pilot study was conducted on one client from Peace Haven unit. This client was chosen by the same procedure, which was intended for the main sample. No major difficulties were met except for having to rephrase the first question in the Zulu translated questionnaire to read thus, (Waqala nini ukugula) when dit you first become ill? The questionnaire was easily understood by the participating client because she was able to explain her pathway to mental health care. This client was not included in the sample thus the validity of the instrument was ensured. Reliability which was the consistency with which the instrument measures what it was supposed to measure, was determined because the responses of the clients in the study were consistent with those obtained during the pilot study.

\section{Ethical considerations}

Written permission was obtained from the Chief Medical Superintendent and the Chief Nursing Manager of the hospital. Verbal approval was obtained from the matron on duty and the professional nurses in charge of the pre-discharge units. Clients were provided with essential information for informed consent and a choice to refuse or terminate their participation at anytime of the study. Respect and confidentiality were maintained and pseudonyms used to protect clients' identity. Permission was also sought from clients to take notes and use a tape recorder during the interview.

\section{Data collection}

On obtaining the permission, the matrons in the different zones informed the chief professional nurses in charge of the pre- discharge units. The researcher then contacted the appropriate clients to set up appointments with the help of the nursing staff on duty those particular days. Weekends were chosen so as not to interfere with the daily routine and the running of the units.

The researcher had to introduce herself, and the research topic to the nursing staff in the units so as to gain cooperation and support. The nursing staff also assisted in the identifying of first admission clients and in briefly explaining their mental state at the time.

The researcher scrutinized the files of those that were selected for the interviews. More background information was obtained from the files and jotted down. The interviews were conducted in a doctor's room within the unit. The initial introduction between the client and the researcher was done.

The client was informed about the research, its purpose, confidentiality and the client's right to refuse to participate if he/she so desired. The client was asked to sign a written consent to agree to participate. Permission was sought from the client to use a tape recorder and to take notes 
during the course of the interview to ensure that no collateral information was lost. A pseudonym was used to protect the client's identity and confidentiality was maintained at all times.

\section{Data analysis}

Data analysis was done manually through transcribing recorded interviews and reviewing the notes taken during interviews so as to ensure that no information was lost. The information gained was used to answer the research questions and to match these responses to the five levels and four filters of the conceptual framework of the study. The information was analysed according to the following categories: demographics, first provider of care, pathways to care from first provider to admission and the delay between recognition and admission, the decision making on the provider or service, satisfaction with health care and preferred health provider and lastly the time delays experienced.

\section{Sample Characteristics}

The sample size was fifteen (15), consisting of eight (8) females, and seven (7) males.

The age distribution of the sample in Table I showed to be between 10 and 59 years. Females were evenly distributed amongst all age groups. There was a preponderance of males in the 20-29 age group.

Thirteen clients were single and two clients both female were married. All clients had primary and secondary education, none were illiterate nor had tertiary education.

All clients were unemployed except for one who was employed as a domestic worker. None were self-employed.

\section{Table I : Age distribution}

\begin{tabular}{|l|l|l|l|}
\hline AGE & FEMAIE & MAIL & TOTAL \\
\hline $10-19$ & 2 & 1 & 3 \\
\hline $20-29$ & 2 & 5 & 7 \\
\hline $30-39$ & 2 & 1 & 3 \\
\hline $40-49$ & 1 & 0 & 1 \\
\hline $50-59$ & 1 & 0 & 1 \\
\hline TOTAL & $\mathbf{8}$ & $\mathbf{7}$ & $\mathbf{1 5}$ \\
\hline
\end{tabular}

Two females were receiving disability grants. Thirteen clients in the sample were Africans and Zulu speaking, and two were English speaking with one White and one Indian. The referencing of participants was by number, for example Client 1 up to Client 15 and the results confirmed the above mentioned distribution.

\section{Results}

Pathways showed that for three clients the first provider of care were faith healers, three were seen by traditional healers, one was seen at the primary health care clinic, five were seen by a general practitioner and three clients were provided with care at the district hospital (Table II).

The pathway dealt with the steps or consultations taken by the client before being admitted to a mental health institution. The bold line represented the first pathway and the broken line presented the subsequent pathway taken by the client to the mental health institution. The double lined boxes indicated the decision-maker, who decided the choice of provider and service to be consulted. The FIGURES I-3 illustrate the examples of pathways taken and the delays as seen in the study.

\section{The decision making on the provider or service}

Table III showed that close family members such as parents, husband and brother made the decision on choice of the provider for the seven clients. Community members were involved in choosing for the two clients. The South African Police Services were also involved in bringing some of the clients to the health care providers for consultation. Two clients decided on themselves which provider to consult.

\section{Satisfaction with health care and preferred health provider}

Figure 4 showed that one client was satisfied with the traditional healer's care who organized his admission to the mental health institution (client 8). Client 6 was satisfied with the faith healer, because she felt better after treatment. Client 15 was satisfied with a primary health care clinic, citing that he had his freedom, unlike in the hospital where he was locked up behind bars. No client was satisfied with the general practitioner because there was no examination or consultation with the client, except to fill in forms. Four clients were satisfied with district hospital care and eight

\section{Table II: First provider}

\begin{tabular}{|l|l|l|l|l|l|}
\hline $\begin{array}{l}\text { Faith Healer } \\
\text { (FH) }\end{array}$ & $\begin{array}{l}\text { Traditional Healer } \\
\text { (TDH) }\end{array}$ & $\begin{array}{l}\text { Primary Health Care Clinic } \\
\text { (PHCC) }\end{array}$ & $\begin{array}{l}\text { General Practitioner } \\
\text { (GP) }\end{array}$ & $\begin{array}{l}\text { District Hospital } \\
\text { DH) }\end{array}$ & TOTAL \\
\hline 3 & 3 & 1 & 5 & 3 & 15 \\
\hline
\end{tabular}




\begin{tabular}{|l|l|l|l|l|}
\hline CLOSEFAMIIX & SELF & COMMUNITY & SAPS & TOTAL \\
\hline 7 & 2 & 2 & 4 & 15 \\
\hline
\end{tabular}

Mallet, Bhudra, Hutchinson, Der and Leff (1999:475) who found that the general practitioner was the most common mode of referral to mental health care. This difference was due to the difference in the demographic characteristics of the two samples.

clients were satisfied with the mental health institution because positive and negative symptoms were disappearing.

\section{Time delays}

The results appearing in Table IV showed that there were delays in seeking appropriate western mental health care. In about eight (8) clients the delay was more than two and a half years. For some clients, the delay was less than six months, and others a year to more than one year.

\section{Discussion}

This study despite its limitations provided an interesting picture of the pathways to mental health care. There were no studies in this country which could be used as a basis for comparison of current findings except for studies in other countries.

\section{Pathways}

The findings indicated that the first provider of care consulted depended on family support, location of provider of care, financial implications, how the family had interpreted the mental illness and the seriousness of the presenting symptoms. This was in keeping with the findings by Gater et al (1991:764). These researchers recognized that most referral-pathways were from the indigenous healers, especially in Rawalpindi and Bangalow districts. Some clients verbalized that if the family cared and had the financial means, proper consultation would have been initiated. (Kade ngaqala ukugula kodwa abasekhaya benganakile). I have been mentally ill for a long time by my family took no notice of this). (Client 10)

The findings also showed that if mental illness was interpreted as bewitchment (ukuthakatha) then a traditional or faith healer, was the first provider of care to be consulted, because of their expertise in dealing with African magic or ( $U k u f a k w a b a n t u$ ) and faith healers were living in the same community as the client and had the reputation of healing certain illnesses completely including mental illness. (Umah wangisa kwiSangoma esalapha omunye umfana owayegula njengami) succeeded in curing a guy who was mentally ill like me). (Client 10). Peu, Troskie and Hatting (2001:54), stated that people in communities consult traditional and faith healers, because of shortage of equipment in health care centers, lack of transport and inadequate information about what health care services were available. Secondly traditional and faith healers were respected, acceptable, accessible and available for continuity of care. For this study, the first port of call was the traditional and faith healers which was not in line with the findings by Balestrieri, Bon, Rodrguez-Sacristan and Tansella
Five clients in this study were seen by a general practitioner through the involvement of the South African Police Services (SAPS) because of violent and aggressive behaviour. According to the $1^{\text {st }}$ level and $1^{\text {st }}$ filter of the conceptual framework adopted from Goldberg and Huxley (1992:4), the identification of mental illness in the community depended on how the individual and family perceived mental illness, their beliefs and values as well as the cultural background of the individual. If bewitchment or ukufa kwabantu was suspected there would be delays to seek relevant mental health care (Ngubane 1977:38).

\section{Pathways to care from the first provider to the time of admission}

The results showed short and long pathways to mental health care (Table IV). Some of the short pathways were attributed to the severity of the first signs of psychotic features that the client presented. Aggressive violent disruptive and public undressing behaviours were the ones that prompted relatives and the public to seek appropriate mental health help (Casey, 1990:10). Although filter 1 was most permeable given the high rates of psychiatric morbidity in the general population, it was clear that a substantial number of clients failed to seek assistance.

The clients that had short pathways to mental health care were those that were a danger to themselves and to the public and that also undressed themselves in public. The majority of these clients were brought by the SAPS to general practitioner's rooms or a mental health institution for admission (Burnett et al. 1999:475).

Marino, Gallo, Ford and Anthony (1995:1143) talk about an an incident mental disorder was seen by a specialist in a mental health without being seen by a general medical doctor. This study was in line with this By Pass because of

\section{Table IV: Time delays before formal contact}

\begin{tabular}{|l|l|}
\hline MONTHS & CLIENT \\
\hline $0-6$ & 3 \\
$7-12$ & 1 \\
$13-18$ & 1 \\
$19-24$ & 1 \\
$25-30$ & 1 \\
$31>$ & 8 \\
\hline TOTAL & 15 \\
\hline
\end{tabular}


those clients that required urgent psychiatric assessment and treatment due to their serious psychotic features. Gater and Goldberg (1991:95) \& Balestrieri et al ( 1994:648) associated the shortest total delays with appearance of psychotic symptoms, disturbed behaviour and self-harm.

The results also showed that clients with insidious onset of mental illness such as the ones who prayed continuously were not recognized in time as mentally ill, as well as those that were abusing alcohol and drugs. These results were also observed by Gater and Goldberg ( 1991:92), who claimed that alcohol and drug related problems had a long interval before seeking care and consequently had the longest total intervals.

\section{The decision-maker on the choice of the provider or service}

Table III results showed that family members were the ones that made the decision as to who to see and where to take the client for consultation in seven clients. In keeping with other research studies emphasis was on the family or friends support as the major guide and support for the client or even in determining the compulsory admissions in $\mathrm{MHI}$ involving the police (Davies, Thorncroft, Leese, Higgingbotham and Phelan 1996:536, Koffman, Fulop, Pashely and Coleman 1999:240, Cole, Leavy, King, JohnsonSabine and Hoar 1995:773).

Four clients of the sample had the SAPS involved in bringing them to mental health services for professional help. Burnett, et al (1999:482) defined police involvement as when the client was taken into care by the police either from a public place or following a request from the clients family. Koffman et al (1997:240), Cole et al (1995:773), Davies et al (1996:533) and Gater and Goldberg (1991:95) all agreed that police involvement shortened the clients journey to mental health care because of presenting violent and self-harm psychotic behaviour as well as the absence of family or friend support system.

\section{Satisfaction with care and preferred health provider}

The results in Figure IV showed that most clients were satisfied with the care given to them especially in district hospitals and the mental health institution, because this was where proper treatment was ordered and given. All clients attributed their satisfaction to the fact that they could think more clearly and were getting better everyday. (Uwelewele womsindo ebengiwuzwa ezindlebeni awusekho). (The ringing and cluttering of noises I used to hear is no longer there.

Client 11 (Ngiyalala manje, ngiyadla kahle futhi ngivageza) the worrying symptoms like auditory hallucinations, sleepless nights were over, poor appetite and poor hygiene had improved.

\section{How are the pathways influenced by demographic factors}

The findings showed that most of the African clients (13) consulted with faith and traditional healers and these results were in line with those of referral pathways from indigenous healers as observed by Gater el al (1991:764). The results also showed that the White and the Indian clients (2) consulted a general practitioner as their first port of call when the first signs of psychotic features appeared. The belief system of bewitchment/sorcery as identified by Ngubane (1977:30-46) and Buhrman (1982:877), was stil] entrenched in the way of thinking and lifestyle of the African people thus long periods of delay were experienced. Traditional/faith healers lived with clients in the communities, were accessible 24 hours and reasonable in price than western biomedical staff especially in rural and disadvantaged areas. This was supported by Gater et al (1991:764), Nevin (2000:14) and Peu et al (20)1:54), who advocated that education, integration and working with the faith and traditional healers in the recognition and referral of the mentally ill clients to be practiced. Poverty and unemployment of most clients seemed to be a problem in consulting their general practitioners and having access to mental health services because of financial constraints (Commander, Sashi Dharan, Odell and Surtees 1997:319).

\section{Delays along the pathway to mental health care}

The delays in getting proper mental health care was evident and supported by the high number of clients (8), (Table IV) which showed how entrenched the belief system of bewitchment / sorcery was amongst Africans (Edwards, Jainarain, Randeree, Rzadkowolski and Wessels 1982:99, Swartz 1998:14, Daynes \& Msengi 1979:307). Ngubane (1977:101), Gumede (1990:54) and Shai-Mahoko (1996:31) had stated that $80 \%$ of African population still consulted their traditional and faith healers for their illnesses. It was also important to understand culture and mental health and to remember that human activity was not free from cultural influence (Swartz 1998:5).

Pillay (1993:84), observed a 5.8 weeks over a year in attendance when clients first suspected that they were ill. This depended on the nature of illness unlike with mental illness especially when the onset was insidious. This delay of Africans in coming late to the health service for assistance was also supported by Uys (1986:28) and Koffman et al (1997:240), where they all agreed that these clients did not present early with mental health problems until it was too late to prevent admission to a mental health institution. (Ngayekelwa ngaba kithi, manje ngila esibhedlela) My family ignored my mental illness now l am here in hospital. Client 3.

Gater et al (1991:767) reported that the delay between first developing symptoms and first seeking care varied from thirty two - one week in all the centres that the surveys were done. For this study the lowest delay was six months for three clients in the sample, and the longest delay was sixteen years for (8) clients. The delays at the main health providers, which were the traditional and faith healers, primary health care clinics, general practitioner, district hospital and mental health institution, were depicted in Table IV. 
This study showed that the highest delays in clients seeking proper mental health care was amongst the traditional and faith healers. This was supported by the changing of these healers, due to lack of improvement in their illness and dissatisfaction with the treatment. This in turn resulted in delays of many years.

According to this study the clients passed through filter 1 - identification of mental illness in level one, which was the community. A few clients moved to the second level and were filtered through the second filter where either the family members or community had the ability to detect the mental disorders. Those that were detected managed to be referred to the third level and filter where they were seen at the district hospital or even transferred to the mental health institution. There were eight clients that delayed and did not filter through because they never consulted the health professionals but were first seen by traditional and faith healers.

This study had also shown that clients defaulted treatment after having been stabilized in District Hospital and were attributing this default to economic factors.

The study showed that $80 \%$ of clients were unemployed and single, which made them more permeable to fourth and fifth filters (Commander et al, 1997:315). One client defaulted treatment because of his siblings negative reference to his treatment (Phuza amaphilisi akho okuhlanya). Take your tablets for madness. This remark is in keeping with what Cole et al, 1995:774 cited Harrison et al, 1989, stating that mental illness carry more stigma in black communities, which when combined with other factors like unemployment and poverty, might explain the delays in reaching services and an increased likelihood of adverse pathways.

\section{Recommendations}

In the light of the findings and problems identified in this study, the researcher made the following recommendations:

\section{Psycho-education}

- Health professionals should embark on educating traditional and faith healers in the concepts of mental illness, the need to take medicines and follow up care and recognition of signs for referral to health professionals, thus shortening the clients' mental journeys to proper health and reducing disability.

- Community/public education and awareness campaigns on mental health should be implemented in order to reduce stigma and discrimination and increase the use of mental health services and bring mental and physical health care closer to each other.

- $\quad$ Education of the SAPS about how to respect and handle mentally ill patients so as to avoid them treating the clients like common criminals.

\section{Research}

The findings of this study suggest that further research was needed that will take the following points into consid- eration:

- Increasing the sample size.

- Interviewing of family members, friends and other relevant people who have been in contact with the client under study for collateral information.

- Period of data collection should be approximately six months to have a broader view of the study.

- The pathways of care and satisfaction of those clients who never reached the MHI.

\section{Limitations}

The research was limited to the first admissions in predischarge units of the mental health institution. The sample size was small and therefore cannot be generalized to other studies.

-Families, friends or other people who had been in contact with clients were not interviewed for collateral information. This study would have benefited from more detailed examination of how separate services especially faith and traditional healers, general practitioners and district hospitals managed individual clients.

\section{Conclusion}

The pathways to mental health care are not static events or strategies, but an ongoing process in the search of an ideal care-giver. It is a process dependant on a wide range of bio-psychosocial factors which need to be understood individually. The study has provided useful information about the pathways taken by clients to mental health care. It highlighted the delays within the faith and traditional healers, delays with the client and his or her family in recognizing first signs of mental illness and seeking appropriate professional help. Cultural background of an individual and how mental illness was interpreted according to his or her value system determines who and where to go for help.

The study has indicated the need for integration of faith and traditional healers into the health system, so as to prevent delays and also non- involvement of family members and neighbours in the care of mentally ill clients in order to lessen, the stigma attached to mental illness.

\section{References}

BALESTRIERI,M; BON,MG; RODRGUEZSACRISTAN, A \& TANSELLA, M 1994: Pathways to Psychiatric Care in South-Verona Italy. Psychological medicine. 24: 64 1-649.

BUHRMANN, MV 1982: Lifestyle and disease. Thwasa and Bewitchment. South African Medical Journal. 51 : 877 879 .

BUHRMANN, MV 1977: Western psychiatry and the Xhosa Patient. South African Medical Journal. 51 : 464-466. BURNETT, R; MALLET,D; BHUGRA, G; HUTCHINSON, G; DER, G \& LEFF, J. 1999: The first contact of the patients with schizophrenia with psychiatric services: social factors and pathways to care in a multi-ethnic population. 
Psvchological Medicine. 29: 475-483.

BURNS, N \& GROVE, SK 1987: $3^{\text {rd }}$ ed. The practice of nursing research, conduct, critique and utilization. Philadelphia: W.B Saunders Company.

CASEY, PR 1990: A Guide to Psychiatry in Primary Care. Petersfield: Wrightson Biomedical Publishing LTD.

COLE,E; LEAVEY,G; KING,M;JOHNSON-SABINE,E\& HOAR, A 1995: Pathways to care for patients with a first episode of psychosis. A comparison of ethnic groups. British Journal of Psvchiatrv. 167: 770-776.

COMMANDER, MJ;SASHI DHARAN, SP; ODELL,SM \& SURTEES, PG 1997: Access to mental health care in an inner-city health district. I: Pathways into and within specialist psychiatric services. British Journal of Psychiatry, 170: 312-316.

COMMANDER, MJ; SASHI DHARAN, SP; ODELL, SM \& SURTEES, PG 1997: Access to mental health care in an inner- city health district. II: Association with demographic factors. British Journal of Psvchiatry. 170: 317-320.

DAVIES, S; THORNCROFT, G; LEESE, M; HIGGINGBOTHAM, A \& PHELAN, M 1996: Ethnic differences in risk of compulsory psychiatric admission among representative cases of psychosis in London. British Medical Journal. 312: 533-536.

DAYNES, G \& MSENGI, NP 1979: stern Psychiatry in Transkei. South African Medical Journal, 56: 307-308.

EDWARDS, SD; JAINARAIN, M; RANDEREE, FA; RZADKOWOLSKI, A \& WESSELS, WH 1982: Conversion disorders in Zulu patients. South African Medical Journell, 62: 97-99.

GATER, R \& GOLDBERG, D 1991: Pathways to Psychiatric Care in South Manchester. British Journal of Psychiatry, 159: 90-96.

GATER, R; DE ALMEIDA, B; SOUSA, E; BARRIENTOS, G; CARAVEO, J; CHANDRASHEKAR, CR; DHADPHALE, M; GOLDBERG, D; AI KATHIRI, AH; MUBBASHAR, M; SILHAN, K; THONG, D; TORRESGONZALES, F \& SARTORIUS, N 1991: The pathways to psychiatric care: a cross- cultural study. Psvchological Medicine. 21: 761-774.

GOLDBERG, D \& HUXLEY,P 1992: Common Mental Disorders. A Bio-social Model. London: Tavistock.

GUREJE, O; ACHA, RA \& ODEJIDE, OA 1995: Pathways to Psychiatric care in Ibadan, Nigeria. Tropical Geographical Medicine, 47(3): 125-129.

GUMEDE, MV 1990: Traditional Healers. A medical practitioner's perspective. Braamfontein: Skotaville Publishers.
K 1997: Ethnicity and use of acute psychiatric beds: oneday survey in North and South Thames regions. British Journal of Psvchiatry. 171 : 238-241.

MACDONALD,AM \& KIRKPATRICK,MA Eds. 1989: Chambers students' dictionary. Suffolk: Richard Clay Ltd.

MARINO,S; GALIO, JJ; FORD, D \& ANTHONY, JC 1995: Filters on the pathway to mental health care, I. Incident mental disorders. Psvchological Medicine. 25: 1135 1148.

NEVIN, T 2000: Sangomas._ Bridging the gap between traditional healing and biomedicine. Business Doctor. Issue $4: 12-15$

NGUBANE, H 1977: Body and Mind in Zulu Medicine. London: Academic Press.

PATEL, V 1995: The cross - cultural assessment of depression. Psychiatry in Practice. 2 (1).

PEU, MD; TROSKIE, R \& HATTING, SP 2001: The attitude of community health nurses towards integration of traditional healers in primary health care in North- West Province. Curationis. 24: 49-55.

PILLAY, BJ 1993: A study of the relation between health attitudes, values and beliefs and help-seeking behaviour with special reference to a representative sample of Black patients attending a general hospital. Doctoral Thesis, University of Natal, Durban.

POLIT, L \& HUNGLER 1999: $6^{\text {th }}$ ed. Nursing Research: Principles and methods. Philadelphia: Lippincott.

SHAI-MAHOKO, SN, 1996: Indigenous healers in the North - West province: A survey of their clinical activities in health care in the rural areas. Curationis. 19:31 - 33.

SWARTZ, L 1998: Culture and Mental Health. A South African view. Cape Town: Oxford University Press.

UYS, L 1986: Perceptions of Health and Illness, and Related Practices among the Urban Black Population of Mangaung (Bloemfontein). Curationis. 9: 28-33.

WILSON, HS 1985: Research in Nursing. Menlo Park: Addison - Wesley Publishing Company. 


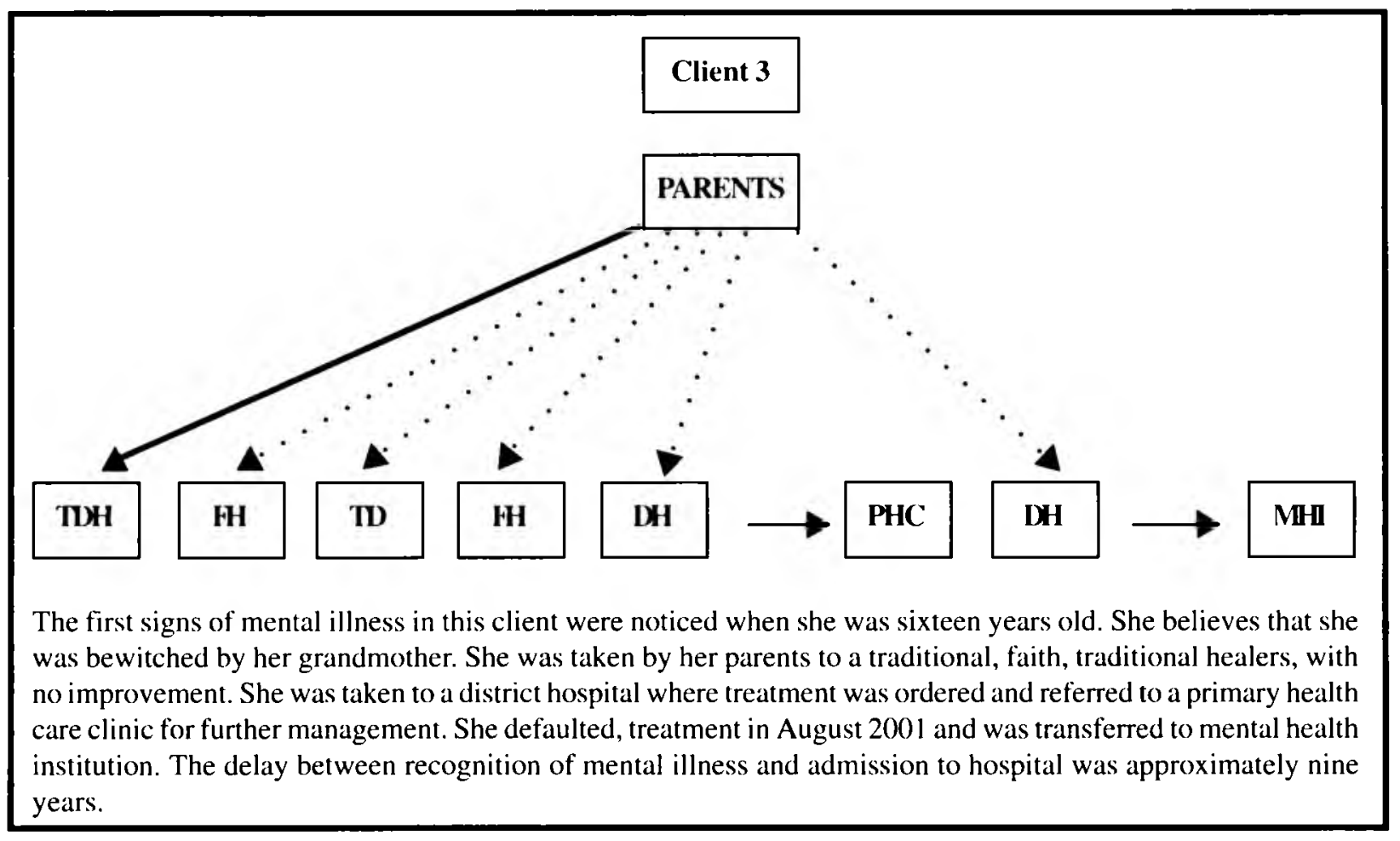

\section{Figure 2: Pathway of client 10}

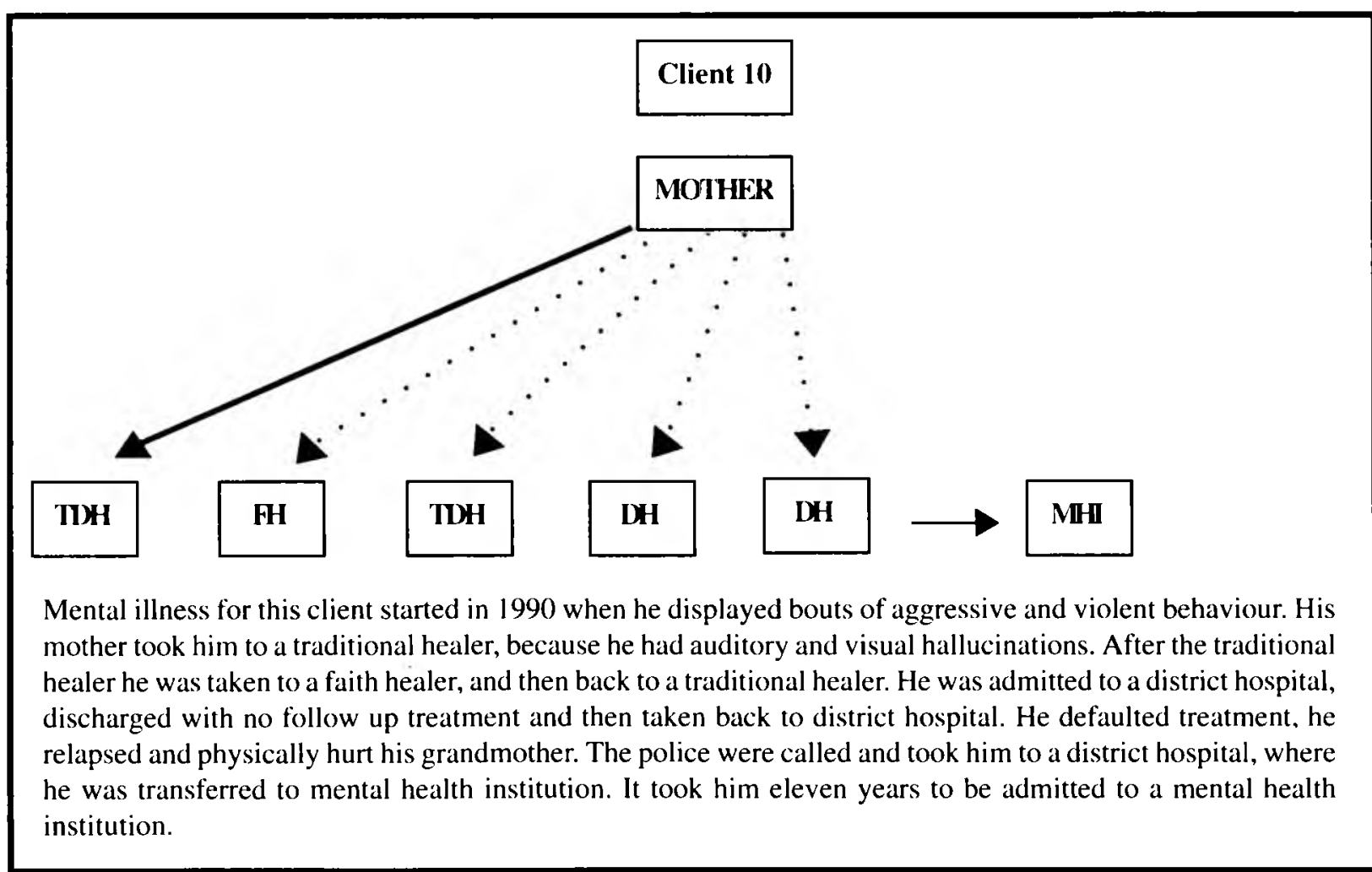


Figure 3: Pathway of client 11

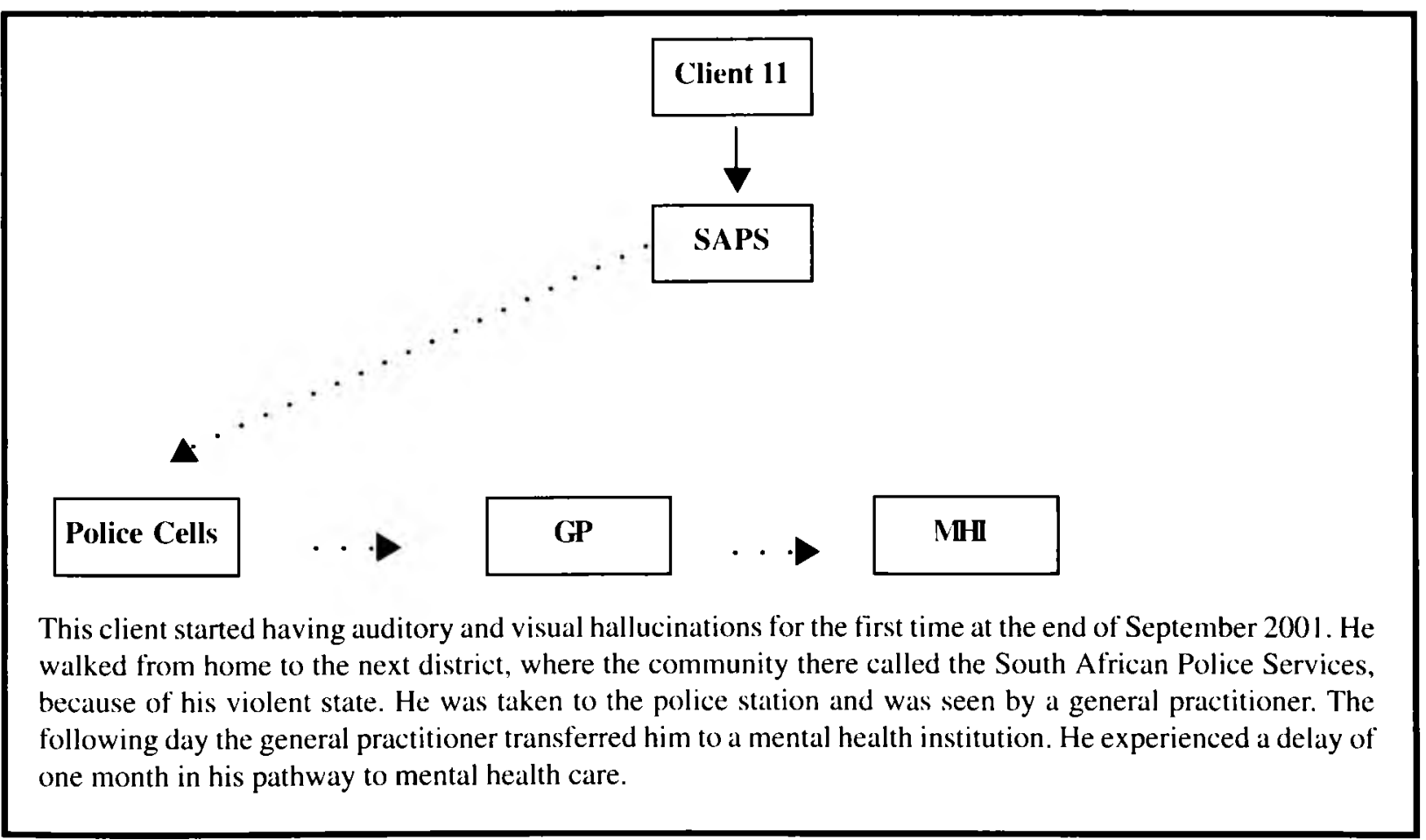

Figure 4 : Satisfaction with care

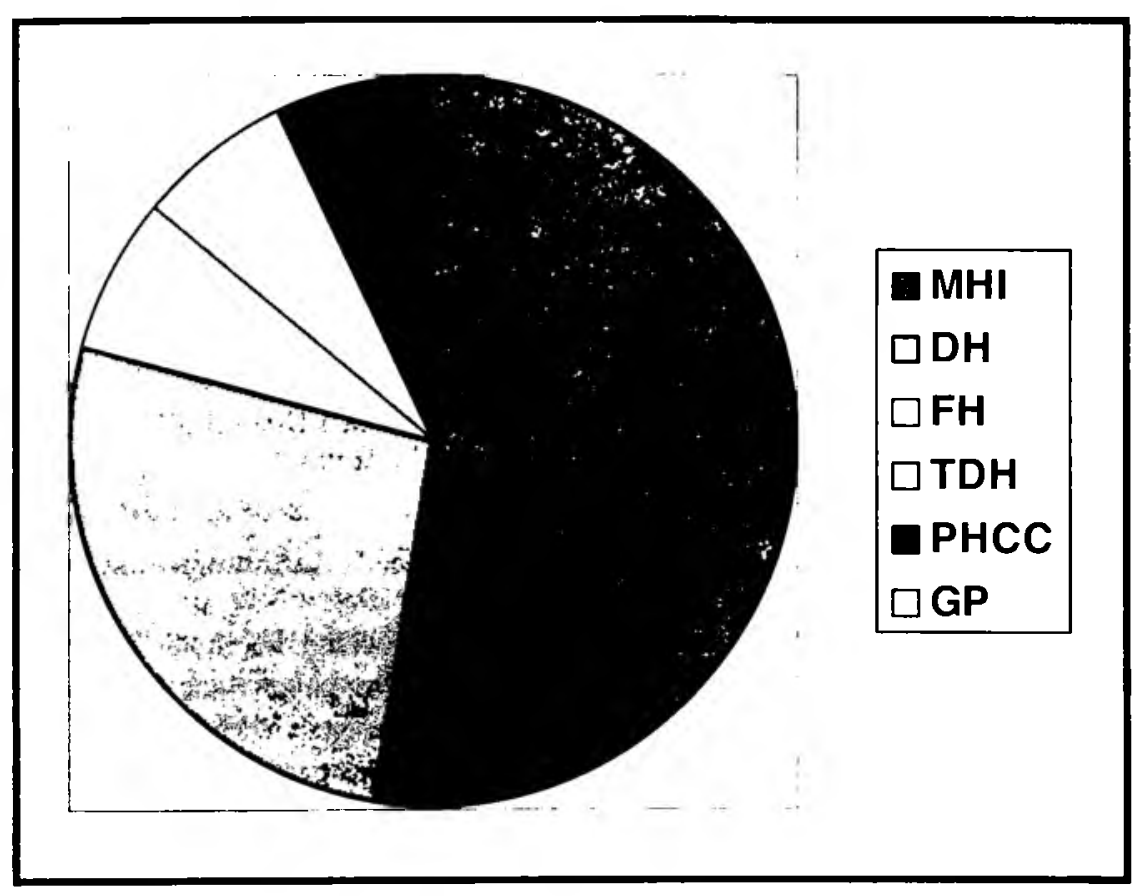

